\title{
Mobilya Tasarımında Ekolojik Malzeme Açısından Kağıt Kullanımı
}

\author{
Sena ŞAHIN ${ }^{1 *}$
}

Öz

Sürdürülebilirlik; gerekli doğal kaynak ihtiyaçlarını gelecek nesillerin yaşam koşullarına zarar vermeden onların da doğal kaynaklara ulaşmasına olanak sunmak şeklinde tanımlanabilmekte ve doğal kaynakların azalmasıyla birlikte günümüzde önem kazanmaktadır. Sürdürülebilir mobilya tasarımlarında ekonomik, yenilenebilir, doğaya zararı az, geri dönüşümü kolay ve az enerjiyle elde edilen ekolojik malzemeler kullanılmaktadır. Böylece doğal kaynaklar verimli kullanılarak atıkların değerlendirilmesiyle tüketim ve doğaya verilen zarar azaltılabilmektedir. Ekolojik malzeme seçimiyle form, işlev, estetik, ergonomi gibi unsurların yanında tasarıma farklı yaklaşım getirilebilmektedir. Tasarımlarda farklı ekolojik malzemeler kullanılmakta ancak çalışmada kağıt malzeme ile yapılan tasarımlar incelenmektedir. Kağıt doğaya zararı az, yenilenebilir, geri dönüşümü kolay, ekonomik malzeme olduğundan ekolojik malzeme sınıfına girmekte ve geçmişten günümüze kadar mobilya tasarımlarında kullanılmaktadır. Kağıt kullanılan bazı tasarımlarda mukavemet, ergonomi gibi konularda sıkıntı olsa da zamanla bunlar çözülerek tasarımlar estetik, ergonomik, işlevsel ve ekonomik hale getirilmiştir. Frank Gehry' nin "Wiggle Side" sandalyesi 1972 yılında oluklu mukavvadan "Easy Edges" (kolay kenarlar) isimli mobilya serisinde üretilmiştir. Malzemenin sıkıştırılması ve kıvrımlı hatları sayesinde mukavemet sağlanmıştır. Düşük maliyet ile ergonomik olarak tasarlanan organik formlu sandalye, döneminin sürdürülebilirlik açısından önemli örneği olmakla birlikte günümüzde Vitra markası sandalyenin üretimini yapmaktadır. Araştırmada literatür taraması yöntemi kullanılmakta olup sürdürülebilir mobilya tasarımlarının önemi ve ekolojik malzeme sınıfında olan kağıt ile tasarlanan mobilyalar incelenmektir.

Anahtar Kelimeler: Ekoloji, Kâğıt, Mobilya, Sürdürülebilirlik, Tasarım.

\section{In Terms Of Paper Use Ecological Materials In Furniture Design}

\begin{abstract}
Sustainability; the natural resource needs of future generations necessary to reach their natural resources without provide to the living conditions can be defined together with the depletion of natural resources in the form of providing and gaining importance. Sustainable furniture designs are economical, renewable and less harm to nature, ecological materials are used and less energy is supplied with easy recycling. Thus, an effective use of natural resources consumption and waste by the evaluation of the damage to nature can be reduced. With the selection of ecological materials, design, function, aesthetics, ergonomics, as well as design elements can be brought to a different approach. Ecological materials are used in different designs, but in the study made with paper material, the designs are examined. Less damage to the paper
\end{abstract}

\footnotetext{
${ }^{1}$ Kocaeli Üniversitesi, Sosyal Bilimler Enstitüsü, İç Mimarlık Ana Sanat Dalı

*ilgili yazar / Corresponding author: sena_sahin54@hotmail.com

Gönderim Tarihi: 18.12.2017

Kabul Tarihi: 12.03 .2018
} 
nature, renewable material because it is easy and economical recycling belongs to the class of ecological materials and furniture designs from the past to the present are used. Strength paper used in some designs, ergonomics on topics such as nuisance, although over time these will be resolved designs that are aesthetic, ergonomic, functional and affordable has been made. Corrugated cardboard Wiggle side chair Frank Gehry's 1972 “ Easy Edges' is called in a series of furniture are manufactured. Thanks to the strength of the compression and curved lines of the material has been achieved. Low cost ergonomically designed with an organic-shaped chair, with the example of the period being important in terms of sustainability today, the brand Vitra, the chair is engaged in the production of. The literature survey method is used in the research and the furniture is designed with the importance of sustainable furniture designs and the paper in ecological material class.

Key Words: Ecology, Paper, Furniture, Sustainability, Design.

\section{GíRiş}

Geçmişten günümüze kadar mobilya tasarımında farklı malzemeler, farklı çözümler ve farklı teknikler kullanılmıştır. Sürdürülebilirlik kavramının ortaya çıkmasıyla çevre bilinci artmış olmakla birlikte doğal kaynakların korunması ve gelecek nesillere aktarılmasının önem kazanmış olduğu da görülmektedir. Mobilya tasarımlarında çevreye olan zararın en aza indirgenmesi ekolojik malzeme seçimi ile sağlanabilmekte ve tasarımlarda ekolojik malzeme olarak seçilen kağıt çeşitleri ile ergonomik, estetik, ekonomik, işlevsel tasarımlar yapılmış olduğu görülmektedir. Mobilya tasarımında ekolojik malzeme açısından kağıt kullanımı başlığı altında ilk olarak araştırmanın temelindeki terimlere ait tanımlamalar yapılmakta olup daha sonra ekolojik malzeme olarak seçilen kağıt hakkında bilgiler verilmekte ve kağıt malzemesi ile yapılan örnek tasarımlar incelenmektedir. Çalışmada detaylı literatür taraması yöntemi ile araştırmalar yapılmış elde edilen veriler doğrultusunda değerlendirmeler yapılmıştır.

TDK(Türk Dil Kurumu)' ya göre ekoloji canlıların hem kendi aralarındaki hem de çevreleriyle olan ilişkilerini tek tek veya birlikte inceleyen bilim dalıdır. Bundan dolayı ekolojiyi insan ile çevresindeki ilişkiler sistemi olarak tanımlamak da mümkün olabilmektedir. Ekoloji aynı zamanda, bir ürünün üretiminden yok oluşuna kadar geçen süreçte (üretim, kullanım, atıklar) çevre sistemlerinin olumsuz etkilenmesini en aza indirgeyecek sistemlerin bilimsel olarak araştırılıp uygulanmasının yollarını aramaktadır(Bostancıoğlu ve Düzgün Birer, 2004, s. 38). Çevre bilimi olan ekoloji ile birlikte sürdürülebilirlik kavramı ortaya çıktığı görülmektedir. Artan nüfus ve üretimlerde ortaya çıkan kirlilik ile birlikte çevre sorunlarının arttığı, doğal kaynakların sınırlı olduğu ancak bireylerin ihtiyaçlarının sınırsız olduğu günümüzde sürdürülebilirlik konusunun önem kazandığı görülmektedir. Şatır(2015)' a göre sürdürülebilirlik 'Çok boyutlu bir tanıma sahip olan kavram genelde, ekonomik, sosyal, kültürel, ekolojik vb. alanların içeriklerinde etkendir. Yaşamın sürdürülebilirliği ön planda ele alındığında, doğal kaynakları tüketmeden, tüketim zorunluluğu olduğunda ise dengeli bir tüketim yaratarak, gelecek nesillerin ihtiyaçlarının karşılanmasında bugünden planlama yapma çabalarını kapsar". Özellikle hammadde kullanımının artması ile üretim sırasında çevre kirliliği artmış bunun sonucunda da sürdürülebilir çalışmalar önem kazanmıştır. Tasarımların üretiminde çevreye verilen zararın azaltılması ve hammaddenin ekolojik malzemelerden seçilmesi ile işlenmesi sırasında zararlı atıklar oluşturulmaması sürdürülebilirliğe katkı sağlamaktadır.

Sürdürülebilirliğe geçiş, birçok firma için daha az kaynak tüketerek üretim yapmak, insanların toplam malzeme tüketiminin azalmasıyla fiziksel ve sosyal kalitenin 
arttırıldığı daha iyi bir sosyal ve ekonomik ortamda yaşamasına yardım etmek için bir öğrenme sürecidir(Turhan, 2011, s. 128).

Sürdürülebilir bir ürün tasarımından bahsedilebilmesi için, ürünü oluşturacak malzemenin eldesinden üretimine, kullanımından tüketilmesine ve bertarafına kadar sürdürülebilir bir sistemden bahsedilmesi gerekmektedir(Öç, 2013, s. 27). Mobilya tasarımlarında sürdürülebilirliğin ekolojik malzemeler kullanılarak yapılan tasarımlarda karşımıza çıktığı görülmektedir. Hammaddesi doğaya zarar vermeyen, kullanım ömrü bittiğinde çevreye zarar vermeden geri dönüşümü kolay olan malzemeler ile tasarlanmış mobilya tasarımları ekolojik tasarımları oluşturmaktadır.

Eko tasarım ise hammadde verimliliği, çevre açısından tercih edilebilecek materyaller, kullanımda verimlilik, söküm ve geri dönüşüm için tasarım, dayanıklılık ve uzun ömür gibi ölçütleri benimsemiştir( Özçuhadar, Öncel, 2011, s. 14). Endüstriyel ve teknolojik gelişmeler aslında doğal kaynakların tüketiminin bir nedenidir. Bu nedenle, gelişmiş ülkelerde ekolojik mobilya tasarımları genel kabul görmektedir. Endüstriyel ve teknolojik gelişmeler nedeni ile imalat arttığından sanayi üretiminin olumsuz etkileri azaltılmaya çalışılmaktadır(Yüksel Ve Kılıç, 2015, s. 358). Dünya genelinde çevre sorunları ve çözümleri, ekolojik çalışmaların fikirleri ilk önemli adım olarak 1972' de Stockholm'de ele alınmış ve " İnsan ve Çevresi" bildirisi yayınlanmıştır. Sonraki yıllarda sürdürülebilirliğe dair yapılan toplantıların arttığı görülmekte olup bu yapılan bildirilerde mobilya tasarımlarını etkileyen sonuçlar olarak tasarımcıların geri dönüşümlü malzemeden yapılan tasarımlarla veya tamamen doğal malzemelerden yapılan tasarımlarla ekolojik çözümlere ulaşabileceği çıkarılabilir.

Dünyanın 1966'da uzaydan çekilen ilk fotoğrafı ile bugünkü karşılaştırıldığında ilk bakışta yedi farkı bulmak hiç de güç değildir. Doğal ormanların \%80'i yok edilmiş, son 30 yılda doğal kaynakların üçte biri tüketilmiş, son 50 yılda ortalama sıcaklık bilinen en hızlı şekilde artmıştır. Bugün ise bir milyardan fazla insan temiz su kaynaklarına erişmekte güçlük yaşamaktadır(Turhan, 2011, s. 126). Günümüzde mobilya tasarımlarında ekolojik malzeme kullanımı tasarımcıların isteklerine göre değişiklik gösterebilmekte kısacası tasarımcıların malzeme seçiminde birçok tercih hakları bulunmaktadır. Ancak imalat sürecinde çevreye zarar verecek atık oluşturmamak ve tasarımları direk olarak ekolojik bir malzeme ile yapmak dünyanın karşı karşıya kaldığı çevre sorunlarına bakılacak olursa tasarımcılara ekolojik tasarımların zorunlu hale getirilmesi gibi bir olasılığın söz konusu olabileceği düşündürmektedir.

Ekolojik malzemelerin birçok farklı çeşidi bulunmaktadır. Yüksel (2016) 'e göre bu malzemeler; Ahşap Köklü Malzemeler(Ahşap ve Levhalar, Bambu ve Rattan), Lifler, Kompozit Malzemeler, Geri Dönüştürülmüş Kâğıt, Biyo Bitkiler-Biyopolimerler ve diğer malzemeler olarak sınıflandırılmaktadır. Bunlardan kağıt ve kağıt ürünleri ile yapılan tasarımlar ise çalışmanın temel inceleme konusunu oluşturmaktadır.

\section{KÂĞIT VE KAĞIT ÜRÜNLERI ILE TASARLANAN MOBíLYALARIN INCELENMESI}

TDK( Türk Dil Kurumu) da kâğıt " Hamur durumuna getirilmiş türlü bitkisel maddelerden yapılan, yazı yazmaya, baskı yapmaya, bir şey sarmaya yarayan kuru, ince yaprak”, karton ise "Kâğıt hamuruyla yapılan, ayrıca içinde bir veya birkaç lif tabakası bulunan kalın ve sert kâğıt" şeklinde tanımlanmaktadır. Kâğıdın ana maddesi olan selülozun liflerinin ince tabakalar haline getirilmesiyle elde edilmektedir. Genellikle odundan elde edilen selüloz, yüksek basınç altında yabancı maddeleri gidinceye kadar ısıtılmaktadır. 
Hamur haline getirilen bu malzeme ise beyazlatılarak kurutulmakta ve daha sonra istenilen şekil kâğıt hamuruna verilebilmektedir. Böylece ihtiyaca göre kâğıt ürünleri elde edilebilmektedir.

Mobilya tasarımlarında birçok farklı malzemeler kullanılmakta fakat sürdürülebilir malzemeler konusunda çok farklı alternatif malzemeler bulunmamaktadır. Sürdürülebilir malzemeler arasında yer alan kağıt ve kağıt ürünlerinin mobilya tasarımlarında kullanımı, üretimi kolay ve özellikle geri dönüşümlü malzeme olmasından, doğaya daha az zarar vermesinden, önemli bir ekolojik malzeme olmasından kaynaklanmaktadır. Mobilyada kâğıt malzeme kullanılmaya başlandığında günlük hayatta karşımıza sürekli çıkan karton gibi basit bir malzemenin baskı ile sıkıştırılarak dayanım gücünün arttırılması ve kıvrımlı formlar ile kullanıma dayanımı artırılmaya çalışılmıştır. Böylelikle kâğıt malzemeden dayanımı yüksek, estetik, hafif ve ekonomik tasarımlarla geleneksel mobilya tasarımlarına sürdürülebilir alternatif tasarım anlayışları geliştirilmiştir. Geçmişten günümüze kadar kâğıt ve kâğıdın çeşitlerinden farklı ürün tasarımları yapılmıştır.

Kağıt ve kağıt ürünleri ile yapılan tasarımlara ilk olarak Gunnar Aagaard Andersen' in 1952-1953 yıllarında tasarladığı Prototype isimli sandalyesi o yıllarda ekolojik malzeme kullanımına örnek olmaktadır. Prototype Sandalyesi gazete kâğıtlarının sıkıştırılarak organik form verilmesinden oluşmakta ve buna ek olarak sandalyenin konstrüksiyonu kümes teli ile desteklenmektedir. Bu sandalye ile birlikte kâğıdın mobilya tasarımlarında malzeme olarak kullanılabilirliği görülmüş olup mobilyalarda sürdürülebilirlik çalışmalarına ağırlık verilmeye başlandığı görülmektedir. Bu sayede kâğıt ve kâğıt ürünleri endüstri ürünleri tasarımında kullanılmakta olup ilerleyen dönemlerle birlikte tasarımlarda gelişmenin sağlandığı görülmektedir(Şekil 1).

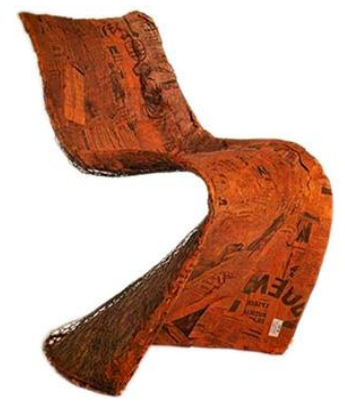

Şekil 1: Gunnar Aagaard Andersen Prototype Sandalyesi (URL- 1)

1968 yılında Peter Murdock' un Londra' da yaptığı sandalye tasarımının lamine edilmiş kâğıtlardan oluşturulmuş olduğu görülmektedir. Murdock' un çocuklar için katlanır ve hafif mobilya olarak tasarlanan sandalyesinin dayanımı konusunda sıkıntılar söz konusu olmuştur ancak tasarımın kâğıdın mobilyada kullanımına destek olmasından ve gelişimine katkı sağlamasından dolayı önemli olduğu görülmektedir. Kâğıdın kolay kıvrılma, bükülme, şekil alma özelliklerinden dolayı tasarımlarda esneklik sağladığı da görülmektedir. Murdock' un sürdürülebilir ürünler serisinin dezavantajı ise ürünlerin tek kullanımlık tasarlanmış olmasıdır. Tasarımın seri üretimi de yapılmıştır(Şekil 2).

Kâğıt hamurunun PLA (biyolojik olarak parçalanan plastik) malzeme ile bir araya getirilmesiyle oluşturulan malzeme ince kesitli, ağırlık ve gerilmeye, neme ve sıcaklığa karşı özellikleri geliştirilmiştir. Ucuz ve atılabilir olması nedeniyle kullanışı bir malzemedir. Murdock' un kâğıt malzemeyi mobilya tasarımında kullanması, ekolojiyi koruma yönünden radikal bir katkı olarak değerlendirilebilir(Yüksel, 2012, s. 2). 


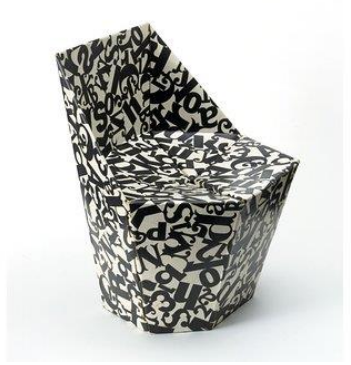

Şekil 2: Peter Murdock Think Sandalyesi (URL- 2)

Bir diğer ekolojik malzeme kullanımı ile ilgili önemli adım ise 1972 yılında " Easy Edges" (kolay kenarlar) isimli mobilya serisinde Gehry' nin tasarımlardır. Seride en dikkat çeken "Wiggle Side" sandalyenin olduğu görülmektedir. Seride oluklu mukavvanın yaklaşık 60 tabakalı halinde sıkıştırılması ile tasarımlar yapılmıştır. Ürünler basit ve kullanışlı olmasının yanı sıra sağlamlığı ve dengeli olmasıyla kâğıdın mobilyada kullanılabilirliğini gözler önüne sermektedir. Ayrıca kıvrımlı formları ve sıkıştırımış oluklu mukavva tabakalarından oluşan dayanımı yüksek mobilyaların maliyeti de geleneksel yöntemlere göre daha ekonomiktir. Mobilya parçaları basit, esnek ve hafiftir. Kolay taşınabilmekte, saklanabilmekte ve montaj edilebilmektedir(Şekil 3). Yüksel(2012)' e göre Gehry kâğıdın düşük taşıma kapasitesini kâğıt hamurunu kalıba dökerek ve presleyerek elde ettiği malzeme ile koltuk ve sandalye üretti. Dayanıklılık ve esneme konstrüksiyonunu sağlama amacıyla mukavva katmanları arasında birbirine ters gelecek biçimde kıvrımlar oluşturdu. Lamine edilmiş mukavva konstrüksiyondan elde edilen bu ürünler zamanla mobilya mağazalarında yerini aldı.

Günümüzde de Vitra markası Gehry tasarımı olan sandalyenin imalatını yaparak satışa sunmaktadır.
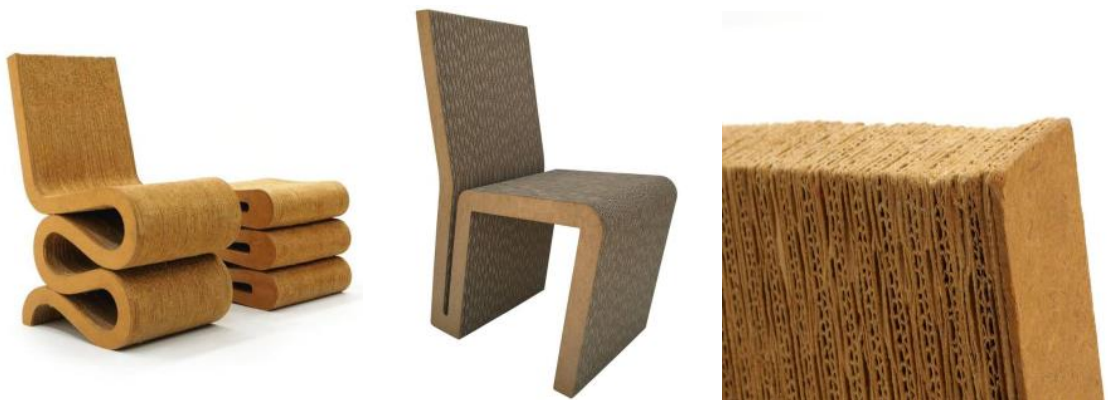

Şekil 3: Frank Ghery “Easy Edges” (kolay kenarlar) isimli mobilya serisi (URL- 3)

Ekolojik malzeme olan kâğıdın tümü ile geri dönüşebilir malzeme olması, maliyetinin ucuz olması, kullanımda esneklik sağlaması, hafif olması, montajının kolay olması endüstriyel ürün tasarımında kâğıdın kullanılabilir olmasını ve kağıt ile yapılan tasarımların gelişmesine olanak sağlamıştır.

Günümüz örnekleri incelendiğinde İtalyan Mimar Giorgio Caporaso' nun tasarımları ekolojik malzeme kullanımı konusunda dikkat çekmektedir. En bilindik tasarımı X2 Chair olan Caporaso tamamı geri dönüşebilir tasarımlar yapmaktadır. Estetik ve basit imal tekniği ile yapılan yenilikçi tasarım ürünlerinin karton ve FSC ahşap bileşenlerinden meydana geldiği görülmektedir. Tasarımlarının parçaları dayanıklı ve uzun ömürlü imal edilmekte olup gerektiğinde onarım yapılması kolaydır. Maliyeti 
düşük olan tasarımlar istenmediğinde kolayca geri dönüştürülebilmektedir. Tasarımlar genellikle sade ve zarif olmakla birlikte tasarımlarda sürekli çizgiler pürüzsüz yüzeyleri meydana getirmektedir(Şekil 4). Sürdürülebilir ürün tasarımlarına destek olan Caporaso ekolojik malzeme olan kağıdın mobilya da kullanımına önem vermektedir.
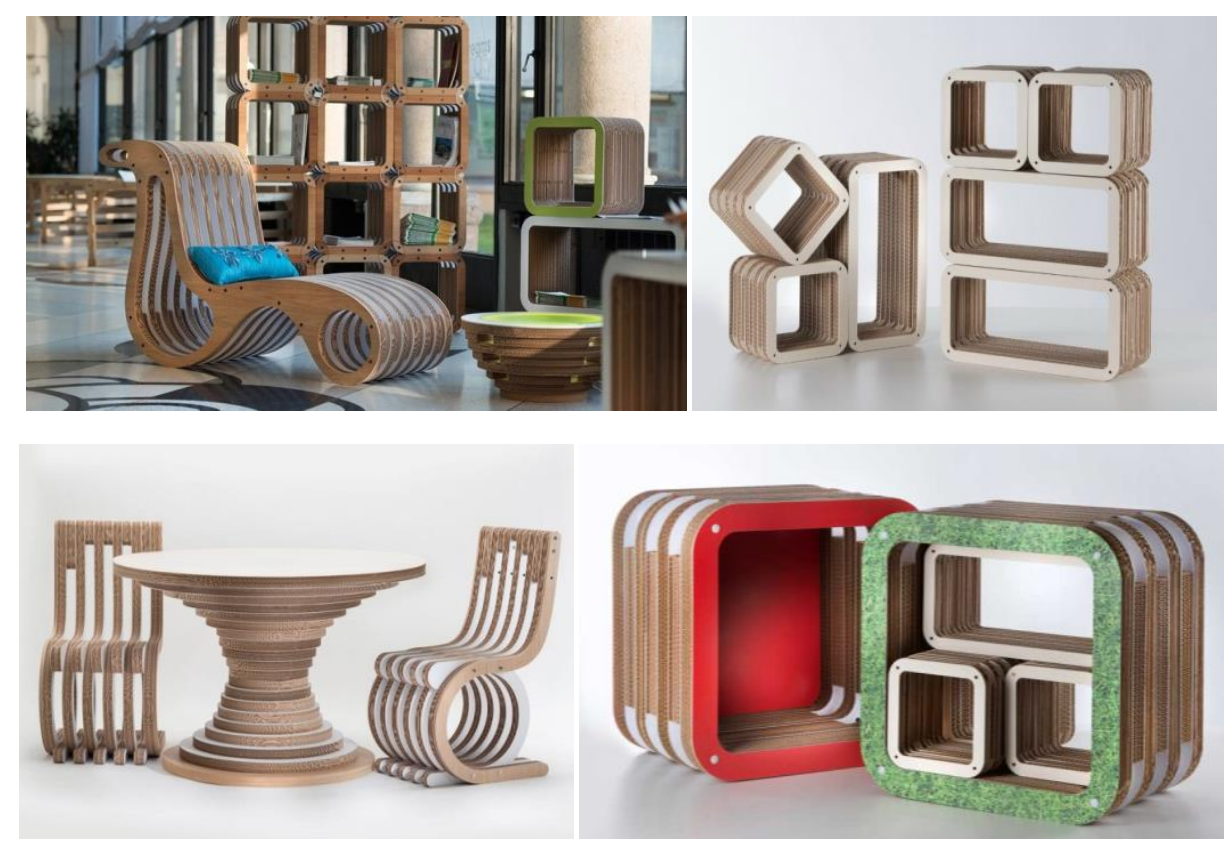

Şekil 4: Giorgio Caporaso' nun Sürdürülebilir Mobilya Tasarım Örnekleri (URL- 4)

Kube Design firmasının ise tasarımlarının tümünün özünde mukavva bulundurduğu görülmektedir. Karton ile yapılan mobilya üretimi tasarımlarda maliyeti düşürdükçe tasarımların çevreye zararlı etkisi de azaltarak seçenekleri daha ekonomik hale getirmektedir. Çevreye duyarlı tasarımları amaç edinen firmanın pratik çözümler sunan kartondan tasarımları hem ergonomik hem işlevsel hem de işlemesi kolaydır. Kube Design mobilya, aksesuar ve aydınlatma gibi çeşitli alanlarda kartondan tasarımlar sunmaktadır. Böylelikle farklı alanlarda ekolojik olan malzeme ile farklı tasarımlar oluşturulduğu görülebilmektedir(Şekil 5).
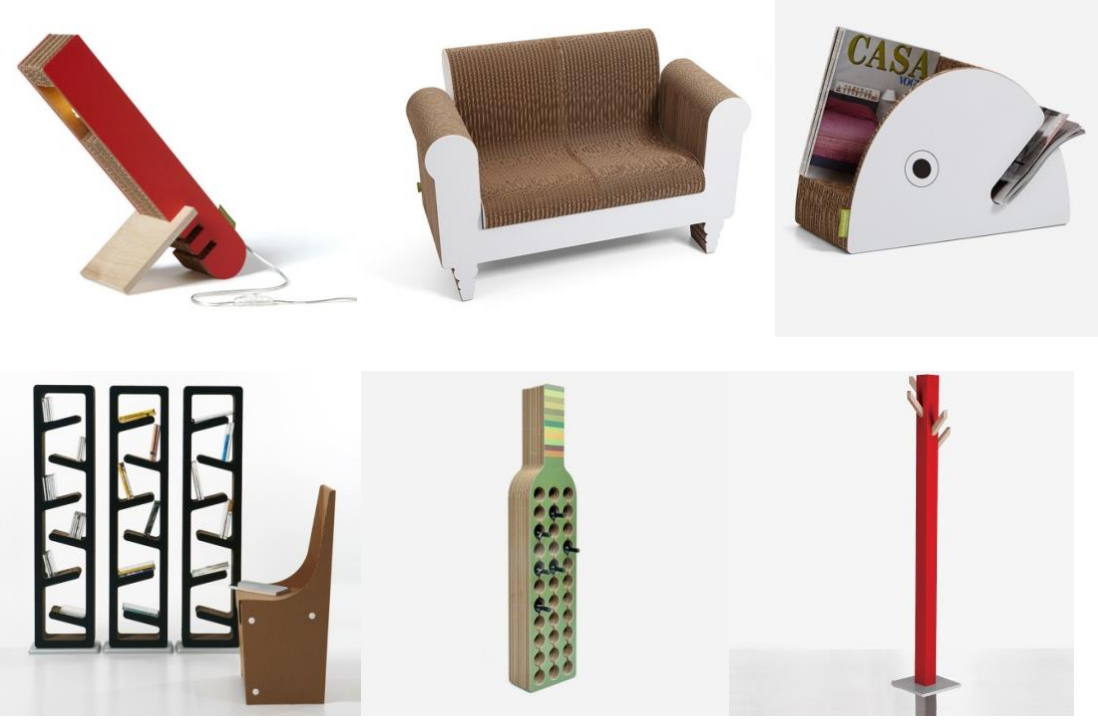

Şekil 5: Kube Design Tasarımları (URL- 5) 
Manfred Kielnhofer' ın 2002 yılında geri dönüştürülmüş kâğıtlarından yapmış olduğu karton sandalye tasarımı günümüzde de çeşitli etkinliklerde kullanılmaya devam edilmektedir. Kâğıt sandalye, halen günümüzde aynı şeklini korumakta olup sandalye kullanılan karton tüplerden yapılmıştır ve bu tüpler geri dönüşümlü kâğıtlardan imal edilmiştir(Şekil 6).

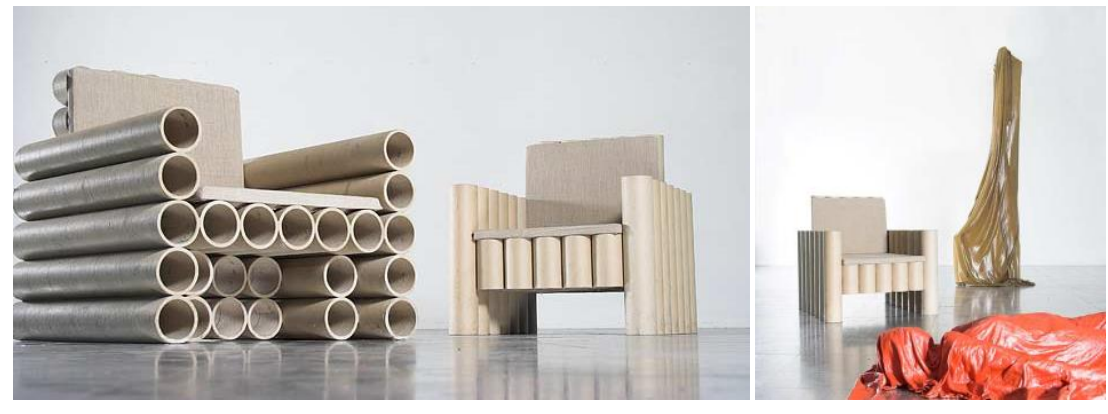

Şekil 6: Manfred Kielnhofer Tasarımları (URL- 6)

Günümüz kâğıt ve kâğıt ürünlerinden yapılan tasarımlarda Mete Mordağ ise 2007 yılından bu yana ev gereçleri, aksesuar, mobilya, şehir mobilyaları, mimari donatılar, yapı elemanları gibi oldukça geniş bir alanda MordagDesign Stüdyosu ile faaliyet göstermektedir. Endüstriyel ürün tasarımlarında ekolojik malzeme kullanan Mordağ, ekolojik dengeyi korumak için yeni tasarım fikirleri ile doğal ve geri dönüşümü kolay materyalleri kullanımına katkı sağlamakta olduğu görülmektedir. Tasarımların tümünü kartondan yaptığı kartonworks serisindeki mobilya tasarımları hem fonksiyonel hem dayanımı beklenenin üstündedir. Genel olarak işlevsel olan mobilyaların estetik, sade, hafif, dayanıklı, taşınmasının kolay ve montajının pratik olduğu görülmektedir.
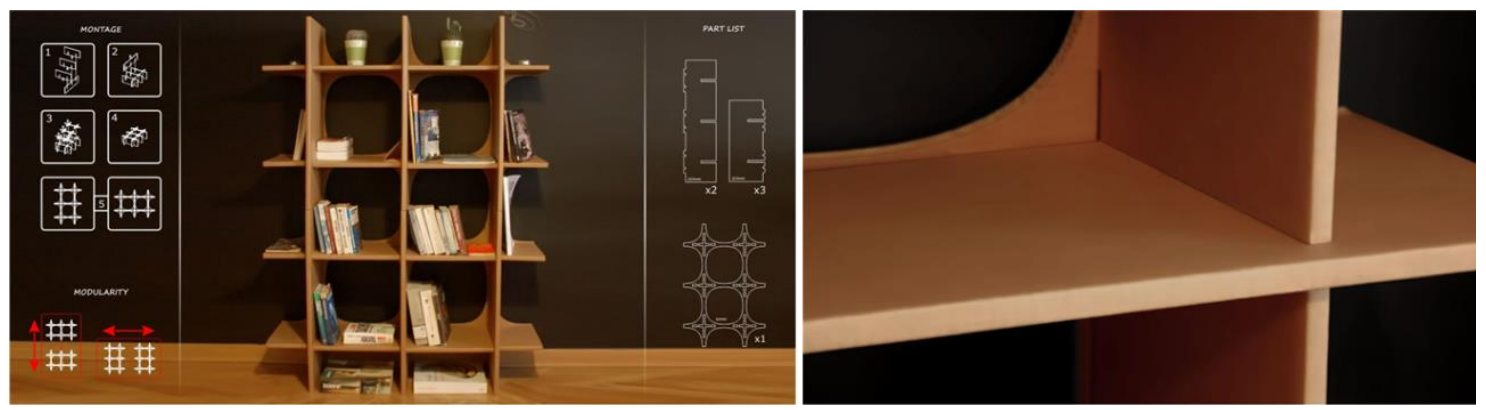

Şekil 7: MordagDesign Antarktika, 2014. (URL- 7)

Kartonworks serisindeki Antarktika isimli kitaplık tasarımı yüksek kalitede mukavvadan üretilen 6 parçadan oluşmaktadır. Antarktika işlevselliğinin yanı sıra hafif, modüler, çevre dostu ve hiçbir bağlantı elemanı veya yapıştırıcı olmadan kolay montajı yapılabilen mobilya tasarımıdır. Mukavva malzemesinin işlenmesi kolay olduğundan tasarımlara organik formlar kolayca verilebilmektedir(Şekil 7).
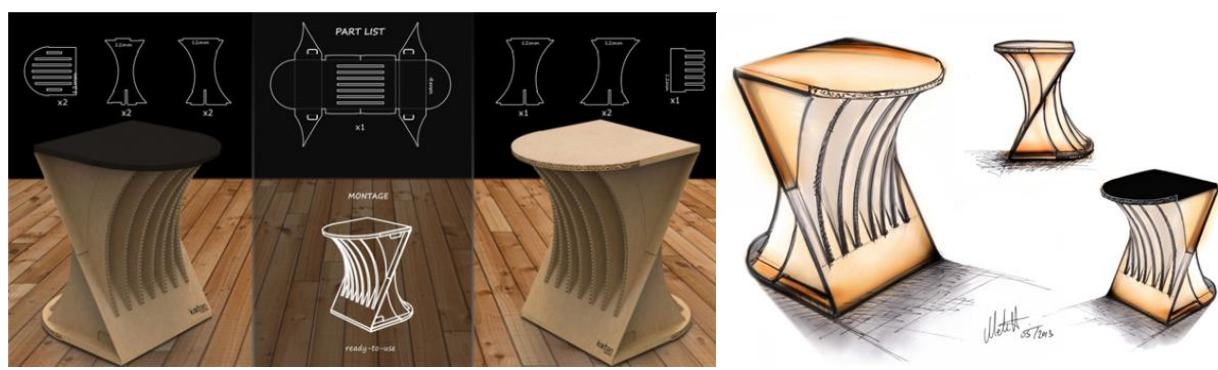

Şekil 8: MordagDesign Kalahari, 2013. (URL- 7) 
Kartonworks serisindeki Kalahari isimli tasarım, yüksek kalitede mukavvadan üretilen katlama ve montaj yöntemleri ile oluşturulmuş bir tabure ve sehpadır. 39x50×50 ölçüsünde hafif olan tasarımın yüksek mukavemete sahip estetik ve çevreci bir tasarım olduğu görülmektedir(Şekil 8).
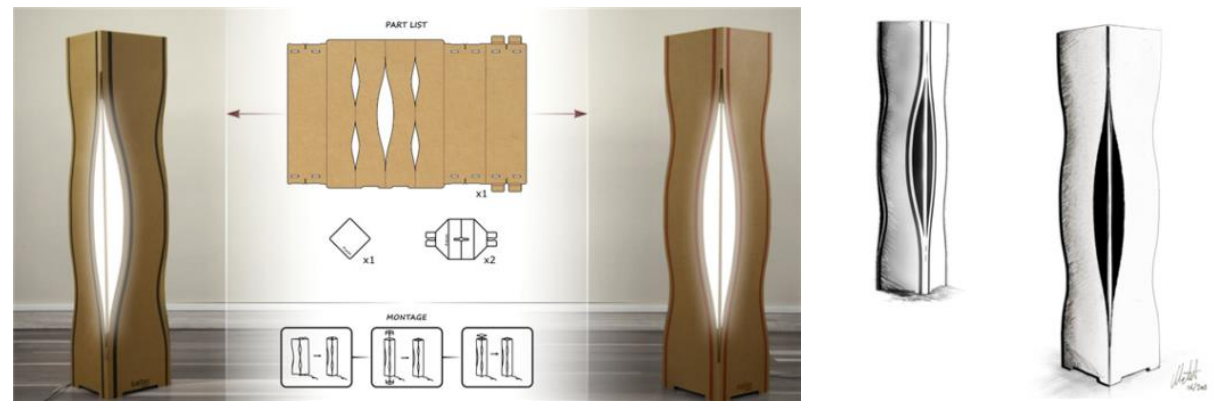

Şekil 9: MordagDesign Kalahari, 2013. (URL- 7)

Kartonworks serisindeki bir diğer ekolojik malzemeden yapılan tasarım ise Meke Lambader' dir. Mukavvadan yapılan Meke Lambader' in içersindeki Ledler sayesinde aydınlatma sağlamakta olduğu görülmektedir. Mukavvanın katlanmasına dayalı olan ürün tasarımın bütün bileşenlerinin geri dönüşüme uygun olduğu görülmektedir(Şekil 9).

Sürdürülebilir malzeme olan kâğıt ve kâğıt ürünleri geçmişten günümüze kadar endüstri ürünleri tasarımlarında kullanılmış olup gelişimi ve kullanılması günümüzde de devam etmektedir. Farklı alanlarda farklı tasarımlarda kâğıt ve kâğıt ürünleri kullanılmakta ve intiyaca cevap veren ürün tasarımları elde edilmektedir.

\section{DEĞERLENDIRME VE SONUÇ}

Sürdürülebilirlik, insanların gelecek kuşakların gereksinimlerine cevap vermesini tehlikeye atmadan, günlük ihtiyaçlarını karşılayabilmesi olarak tanımlanmakta ve çevreye verilen her zarar sürdürülebilirlik kavramı ile ters düşmektedir. Ekoloji veya doğa bilimi ise canlıların birbirleri ve çevreleriyle ilişkilerini inceleyen bilim dalıdır. Sürdürülebilirlik kavramının dünyanın ekolojik dengesinin bozularak çevreye verilen zararlarla birlikte günümüzde giderek daha önemli hale geldiği görülmektedir. Çalışmada; dünyanın ekolojik dengesinin bozulmaması için her alanda sürdürülebilir çalışmalara destek verilmesi sonucuna ulaşılmıştır. Bu sebeplerden dolayı mobilya tasarımlarında tasarımcıların ürünlerin çizimlerinden üretilmesine kadar her aşamasında çevreye duyarlı olması gerekmektedir. İmalat süresince meydana çıkan atıkların değerlendirilmesi veya geri dönüştürülmesi sürdürülebilir çevre için büyük önem taşımaktadır. Sürdürülebilirliğin sağlanabilmesi için imalat süresince çıkan atıkların değerlendirilmesinin yanı sıra mobilya tasarımlarında ekolojik malzeme kullanılması da önemli bir adım olmaktadır. Böylelikle ekolojik malzemeler ile yapılan tasarımlar çevreye zarar vermeden intiyaca cevap verebilecektir. Üretimi ve işlenmesi sırasında az enerji harcanan, kullanım ömrü bittiğinde kolayca geri dönüşebilen malzemeler ile mobilya tasarımı yapılırsa dünyanın doğal dengesinin korunmasına katkı sağlanmış olup kaynak ve enerji tüketimini en aza indirebilecek çözümler ile sürdürülebilirliğe katkı sağlanacaktır.

Çalışmada ekolojik malzemeler sınıfına dahil olan kağıt ve kağıt ürünlerinden yapılan mobilya tasarımları incelenmiş ve kağıt ürünlerinden yapılan tasarımların geçmişten günümüze kadar kullanılmış olduğu görülmüştür. Geliştirilerek kullanımına devam edilmekte olan kağıt mobilya tasarımlarının; estetik, ergonomik, işlevsel, organik, kaliteli ve ekonomik olduğu saptanmıştır. Böylece daha az enerji kullanarak daha az 
çevreye zarar ile mobilya tasarımları mümkün olmaktadır. Pratik kullanıma uygun, montajı ve geri dönüşümü kolay kağıttan oluşan mobilyalar bireylerin ihtiyaçlarına ve kullanımına uygun olduğu sonucuna varılmıştır.

Son olarak; tasarımcıların dünyanın karşı karşıya olduğu çevre sorunlarının artmış olduğu günümüzde, çevreye duyarlı sürdürülebilir yaklaşımlar olan ekolojik malzemelerden tasarımlar ile intiyaca cevap veren ürünler oluşturabilmeleri geleceğimize önemli katkı sağlayacaktır.

\section{KAYNAKLAR}

Bostancıoğlu, Esra Ve Düzgün Birer, Emel, Ekoloji Ve Ahşap-Türkiye' de Ahşap Malzemenin Geleceği, Uludağ Üniversitesi Mühendislik Mimarlık Fakültesi Dergisi, 2, 2004, 37-44.

Öç, Burç, Sürdürülebilir Tasarım: Ürün Tasarımı Ve Üretimi Temelinde Malzemelerin Geri Dönüştürülmesi Bilinci, İstanbul Teknik Üniversitesi Fen Bilimleri Enstitüsü, Yüksek Lisans Tezi, İstanbul 2013.

Özçuhadar, Tuna Ve Öncel, Pınar, Eko- Tasarım, Sürdürülebilir Üretim ve Tüketim Yayınları,4, 2011, s.n.y.

Turhan, Senem, Sürdürülebilir Kalkınmada Endüstriyel Tasarımcının Rolü, Sanat Ve Tasarım Dergisi, 7, 2011, 125-139.

Şatır, Seçil, Sürdürülebilir Kentsel Mekânlar\&Kent Mobilyaları, Tasarım+Kuram Dergisi, $19,2015,1-18$.

Yüksel, Emine, Ecologic Materials Used In Furniture Design, Mugla Journal of Science and Technology, 2, 2016, 125-130.

Yüksel, Emine Ve Kılıç, Murat, Eco-Friendly Approach In Furniture Design, Research for Furniture Industry Proceedings of the 27th International Conference , Gazi Unıversity, 2016, 357-368.

Yüksel, Emine (2012), Mobilya Tasarımında Çevre Dostu Yaklaşımların Tarihsel Süreci, 2050 Sürdürülebilir Gelecek Dergisi, Gizmo Yayıncılık, 2016, s.n.y.

URL-1 Erişim: http://designofthetimes.altervista.org/wpcontent/uploads/2014/02/Gunnar-Aagard-Andersen-1952-53.jpg

URL-2Erişim:http://collections.vam.ac.uk/item/O49115/chair-thing-chair-murdoch-peter/

URL- 3 Erişim:https://www.1stdibs.com/furniture/seating/lounge-chairs/frank-gehryeasy-edges-contour-chair/id-f_5488803/

URL- 4 Erişim: https://eluxemagazine.com/homestech/giorgio-caporaso-paper-chaise/

URL- 5 Erişim: http://www.kubedesign.it/it/default.html

URL- 6 Erişim: http://kielnhofer.at/design.htm

URL- 7 Erişim: http://www.mordagdesign.com/\#/projects/378/1795/ 